\title{
Value Creation of Healthcare Services- Developing a Healthcare Matching Model
}

\author{
Lars Nordgren \\ Associate professor \\ Department of Service Management and Service Studies \\ Lund University \\ Former hospital director \\ Box 882, 25108 Helsingborg \\ Affiliated to Halmstad University \\ Box 823, 30118 Halmstad \\ Sweden
}

Agneta Planander

Senior lecturer and affiliated to the Department of Service Management and Service Studies

Lund University

Sillgränd 7, 26377 Mölle

Sweden

\section{Catharina Wingner Leifland}

Former lecturer,Department of Service Management and Service Studies

Lund University

Björkvägen 1, 22456 Lund

Sweden

\begin{abstract}
Healthcare in Sweden is dealing with problems regarding accessibility for patients. Moreover, there is a lack of an overall model concerning matching specialist care to patients. Against this background, the purpose was to develop a preliminary healthcare matching model and discuss the barriers of this model. Theoretically, the study draws on the concepts of matching and coordination completed with value co-creation. Inspired by action research there was collaboration between the researchers and practitioners in the Skåne Region in Sweden between 2013 and 2016 (case one). Studies of policy documents, several meetings with strategists and analysis of a coordination meeting served as a basis for gathering empirical data concerning the process of coordinating patients and capacity. A completing study concerned analysis of the coordination of care guarantee service to the patients in the Halland Region (case two). Based on a theoretical analysis and analysis of two cases (in two regions) in Sweden it seems that an advanced matching, based on co-creation between patients, referrers and providers, is required in order to balance specialist care capacity to the needs of the patients smoothly. Both patients and providers could benefit from the use of matching healthcare. However, there are several barriers against healthcare matching: the Swedish legislation that includes minor incentives to cooperate between regions, the different cultures in the regions, and the strong professional identity in healthcare.In order to succeed in the notion of healthcare matching, there have to be active cooperation by the stakeholders involved. This article is original in the development of a preliminary model of healthcare matching concerning specialist care.
\end{abstract}

Keywords: accessibility, co-creation, cooperation, coordination, barriers, healthcare, matching, service, value

\section{Introduction: accessibility - a challenge in the Swedish healthcare}

There is pressures on health systems across the world to have connecting links that will create appropriately targeted and accessible services for patients (Saltman, 2014).In Scandinavian healthcare different models have been launched in order to improve accessibility (Ahgren, 2014). One model is to coordinate capacity to patients, which has not been successfully enough (Nordgren \& Ahgren, 2010, SOU 2016:2, see the section "Coordination of patients in two regions"). iii The current organisation of healthcare in Sweden ${ }^{\mathrm{iii}}$, with 21 autonomous regions, is unable to create healthcare of equally good accessibility throughout the country (Winblad \& Hanning, 2013). 
A follow-up January-September 2017 shows that only 72-91 percent of patients receive care within the healthcare guarantee period (Socialstyrelsen, 2018). One reason for this deficiency may be the fact that the producing of care within a limited economic and geographical region, does not in general match the demand for care (Berry \& Bendapudi, 2007). The fact that the regions (county councils) have been responsible for meeting the population's healthcare needs within their catchment area means that their interest in providing freedom of choice across county council's boundaries have been limited (Winblad, 2007). Although there is a need, the coordination of specialist capacity between different units has been insufficiently evolved (Iversen, 2014). The consequence of this is that there may be resources available at one hospital while there is a shortage at another one (Nordgren, 2011), a problem which is relevant also for other countries (Wingner Leifland \& Nordgren, 2017). There are also the difficulties of transmitting the referrals and medical records accompanying the patient's care flow. Moreover, healthcare cannot be stored and the cost structure is highly fixed (Berry \& Bendapudi, 2007). These aspects underline the value of using capacity (Lovelock \& Wirtz, 2007).

In order to improve accessibility a timing care guarantee was introduced in 2005 (Winblad \& Hanning, 2013). ${ }^{\text {iv } I t ~}$ works if it's accompanied by sanctions on care providers to ensure that the guarantee is met (ibid.) Moreover, a patient act was introduced 2015, implying that there should exist available information regarding the supply side of providers, in order to enable free choice of care throughout the country. This law has not significantly changed the way in which the healthcare system works (Myndigheten för vård- och omsorgsanalys, 2016). Still there is a lack of information regarding providers.

In summary healthcare in Sweden is dealing with problems regarding accessibility. Moreover, there is a lack of coordinating and matching specialist care to patients smoothly. Based on a literature review (see the next section) we argue that there is a knowledge gap regarding an overall matching model of capacity and needs. On this basis we claim, that a new way of dealing with accessibility, i.e. matching healthcare, has to be developed.

The article continues with the theoretical framework, the purpose and the method of the study. To illustrate the problems and possibilities with accessibility there is an analysis of how two Regions work towards coordinating capacity to patients. Then follows a discussion concerning the development of a healthcare matching model followed by a review of the field of cooperation across different boundaries with the emphasis on discussing general barriers. Finally, a conclusion is drawn which is based on the discussion of the study.

\section{Theory and literature review - introducing the concept of healthcare matching}

As pointed out above, the different initiatives of creating equal accessibility to care-seekersin the Swedish healthcare have not been successful. None of the initiatives has specifically looked into the capacity and needs in order to establish equilibrium between these aspects. This paper argues for the introduction of 'matching', as an approach to obtain this equilibrium (Nordgren, 2011, Lovelock \& Wirtz, 2007). According to Rothv (2015, p. 4) "matching is economist-speak for how we get the many things we choose in life that also must choose us". ${ }^{\text {in }}$ In public services matching used in the matching of donors of kidneys and patients, matching of school choice and the match for new doctors (Roth, 2015). ${ }^{\mathrm{vii}}$

The intention with the specific concept of healthcare matching (Nordgren 2009, 2011) is to find the right match between the individual and the healthcare providers, concerning for example time and competence. Nordgren (2011) considers a specified form of coordination of healthcare recources and the needs of the patients based on interactions between the matching function, the providers, the referrer, and the patient. It is seen as a specified service of coordinating healthcare capacity with the needs of the patients (ibid). ${ }^{\text {vii }}$

The matching service could be cocreated by customers, providers and a matching unit. ${ }^{\text {ix }}$ Since the late 1990 's, the customer (the patient) has been referred to as a value creator in service management discourse (Normann, 2001, Batalden et al, 2016, Eriksson \& Nordgren, 2018, Osborne, 2018). Normann \& Ramirez (1994, p. 62-63) point at the need of interaction between providers and customers: "it is a key element in the supplier's job to match the valuecreating activities of the particular customer group he or she is addressing, case by case." The degree of interaction might include different stages of integration of services in a continuum (Ahgren \& Axelsson, 2005).

The first stage is full segregation, followed by linkage, including interaction between existing organizational units. The third, coordination, includes interaction in networks, through existing units in order to share clinical information and coordinate different health services. The fourth is cooperation in order to improve contacts between managers. The last is full integration, where pooling of resources creates new organizations, which will meet the needs from patients. Linking the healthcare matching concept with the concept of full integration, we argue that a successful healthcare matching requires a high level of integration. Concerning matching of healthcare a few articles appear in the literature. Nordgren (2011) shows that there are several reasons for the deficient coordination of care to patients (see the 
Introduction). By analysing the effects of the political reforms on free choice of care and care guarantees, Nordgren (ibid.) concludes that an accessibility service based on matching needs to be developed. Another example is how professional service firms in the form of obstetrics practices, coordinate physicians specialized in certain medical problems and match these specialists with patients. Matching and increased specialization among physicians thereby represent two sides of the same coin: patients are matched when they are treated by specifically trained physicians and physicians are specialized by gaining experience from treating patients with a specific diagnose (Epstein et al., 2010). Another example is the use of advanced access scheduling, which requires matching of daily healthcare provider capacity with patient demand (Qu et al., 2007). Fieldston et al. (2014) as well discuss a form of scheduling describing a tool for defining and measuring workload and workforce in a hospital setting in order to match the two. A functional matching is essential for hospital efficiency and satisfaction among staff. These factors will affect accessibility to care (ibid.). Hall (2011) discusses matching of healthcare resources (providers, rooms, equipment, supplies, organs, devices and instruments) to patient needs in time and place as a matter of planning capacity. Duggal et al. (2015) propose a technical solution to the need of improving matching of patient records from disparate systems and providers in order to catch the right patient information in the right time, matched to the right person. In the Swedish healthcare organization, there is a lack of a matching system (Landstingsrevisionen, 2013).

The read articles regarding matching in healthcare describe attempts to plan special course of events such as patient information reaching the right person, advanced personnel scheduling, patients being match to the right specialist etc. Based on these findings in literature we argue that there is a knowledge gap regarding an overall matching model of capacity and needs. This gap we aim to reduce by developing a healthcare matching model.

In summary our theoretical discussion has moved from coordination, via co-creation and integration as a continuum of different stages including "working together" on different levels in the health organization to finally, introducing the concept of healthcare matching being included in the integration continuum.

\section{Purpose}

The current organisation of healthcare in Sweden is unable to create healthcare of equally good accessibilitythroughout the country (see Introduction). One reason for that is that Swedish healthcare is dealing with an undeveloped degree of coordinating capacity to patients. Against this background as well as the knowledge gap regarding the use of matching total capacity and needs in healthcare, this paper has a twofold aim: 1. to develop a preliminary conceptual model of healthcare matching based on empirical findings and earlier research, and 2. to discuss in general the main barriers of healthcare matching.

\section{Method}

The research method was inspired by the methodology of engaged scholarship "...a participative form of research...in studying complex problems." (Van de Ven, 2007). This form of research emergedin the cooperation between the authors of this paper and practitioners (strategists and physicians) in Region Skåne, one of the two regions that were included in the study. Thereby a transfer of knowledge and experience were contributing in the research process. Region Skåne was of interest due to the long queues to healthcare and the need of coordination, while Region Halland was of interest, because it has been top ranked in Sweden as regards reducing waiting list since 2009 .

Theoretically, the study draws on the concepts of matching and coordination in healthcare completed with the concept of value creation.

Literature scanning was done for peer-reviewed articles, on the use of the concepts of matching and coordination in the context of healthcare (46 articles were chosen). The selection criteria were to prioritize articles based on qualitative studies during the period 2003-2016 and being clearly included within the discourse of matching and coordination.

In order to discuss how to develop a preliminary healthcare matching model, studies of policy documents, scientific articles, reports (Region Skåne, 2013; 2015), seven meetings, initiated by the researchers, and attendance at a so-called coordination meeting served as the basis for gathering empirical evidence. The meetings took place at Region Skåne Malmö Office in the period 2014-12-10 to 2016-06-14. At the first seven meetings, present people were a health care strategist, and an accessibility and coordination coordinator, both at Region Skåne and two of the authors. At the coordination meeting, seven accessibility coordinators from different hospitals in the Region were present. The seven meetings lasted between three and four hours. The coordination meeting lasted 6 hours.

All meetings were recorded, transcribed and systematized according to topics such as coordination, matching, availability, capacity and care needs. These topics crystallized out, and were chosen as essential after the first meeting. This was to facilitate both future meetings and the writing of the report. In this way, material from a previous meeting 
could be used in the next meeting. After each meeting a summary was written and analysed in order to provide a basis for the next meeting. The researchers actively participated in the discussions, added knowledge and created frameworks for the discussions.

The research concerning management of the care guarantee service in the Region of Halland (former Halland County Council)is described in Nordgren (2012). This study is used as empirical material, due to that it is still valid concerning accessibility to healthcare. The research was conducted by analysing political and management statements as well as routines used in the Region in an information leaflet dealing with the care guarantee (Halland County Council 2009). The routines is managed by a Care guarantee service unit with regard to how to be informed about waiting lists, vouchers and certificates, which are required in order to obtain care outside the County. To supplement the analysis of the routines two interviews were conducted with the head coordinator of the unit.

Moreover, in the development of the model, there has been several discussions between one of the researchers and the earlier head of a clinic at the University hospital in Skåne.

One of the authors will use the knowledge he gained as a health manager (director) and management consultant in Sweden between 1983 and 2001. During this period he, as a participant observer, systematically made notes regarding managerial work in the field (as Czarniawska, 2007, p. 13 writes: "an employee becomes a researcher"...."such studies - no doubt superior to all other types-..."). A certain experience was the cooperation between hospitals in order to reduce waiting lists (Nordgren, 2003). Another experience was the managing of barriers to the cooperation between hospitals.

\section{Coordination of patients in two regions}

In this section the coordination of care to the patients in the Regions of Skåne and Halland will be described and analysed.

\section{Coordinating care to the patients of Region Skåne}

In this section, we will show how Region Skåne works towards clarifying areas that suffer from accessibility problems and where there are operational activities with released capacity in the healthcare catchment area. The basis of Accessibility coordinators (ACs) work is included in certain praxis (Region Skåne, 2013). ACs at every hospital have the goal to optimise Region Skåne's joint resources for appointments, examinations, and treatments with the aim of working towards the care guarantee being honoured and Region Skåne's patients obtaining care within the publicly financed healthcare provided by the Region. The network of ACs consists of people appointed by the respective hospital administrations, points of contact for publicly financed private healthcare, the healthcare pilot function, and an overall AC manager at the regional level.

Since 2005, coordination models has been developed yearly for the coordination of specialist healthcare guarantee patients, coordination towards released capacity, coordination in the event of changed assignments, and for specific fields of operation. Initially the aim with coordination was to find a temporary solution in order to solve urgent problems (Nilsson, 2016). The total coordination of waiting patients has increased from 22079 patients in 2016 compared with 1869 in 2006 (ibid). In 2017, it was still increasing (Nilsson, 2018). The increase depends on a combination of factors (ibid.):

"Increased information about patient rights and increased knowledge of utilization of available capacity in regular supply. After the statutory care guarantee (in the Patient law) changed referral confirmation text, i.e. coordination begins if expected waiting time exceeds the time frames of the care guarantee's. Increased supply for care guarantee patients through care guarantee agreements. Capacity shortage in recent years, especially regarding nurses, leading to reduced operating capacity and reduced level of beds. "

Work conducted within the AC network aims at creating effective coordination of patients between various actors, i.e. the operational activities conducted within the home administration, existing "healthcare coordinators", and accessibility coordinators at other administrations. Furthermore, ACs must be up-to-date and able to communicate the home administration's assignments and agreements with external healthcare providers, the home administration's waiting situations (range, problems, capacity and waiting times), as well as other administrations' waiting situations. ACs support activities within the home administration when there is a need to coordinate patients or patient groups. They are acting as a link between activities in the home administration and the healthcare pilot when there is a need to coordinate patients or patient groups to/from the Southern Healthcare Region and the rest of Sweden. The healthcare pilot is necessary to use when own and region - internal resources are lacking, and care has to be found outside the county. The usual thing for the AC is to contact the healthcare pilot who then explores the possibilities of obtaining care within the region. Then treatment outside the county is initiated. 
On the instructions of the overarching accessibility coordinator, ACs request data from activities within the home administration regarding, for instance, assignments, production, inflow, and capacity. ACs must have good knowledge of the care guarantee and other patients' rights, and be able to answer questions relevant to their home administrations.

Region Skåne's auditors (2013) assessed that the coordinators' possibilities of implementing their assignments are dependent on close cooperation with the heads of administration and operations.

\section{Analysis of the work of coordination of patients in Skane}

In the text above has been described how an overall system for coordinating patients and their capacity works in practice. Attending and analysing the coordination meetings as well as studying the reports stating the outcome of coordination it seems clear that the present coordination work is not solving the accessibility problems.

Much of the coordination work is done by accessibility coordinators (ACs) and by a regional AC manager. The work conducted within the AC network aims at creating effective coordination of patients between the operational activities conducted within the home administration, existing "healthcare coordinators", and availability coordinators at other administrations. The healthcare pilot is necessary to use when own and regional internal resources are lacking, and care have to be found outside the Region.

The coordination of patients requires information on care capacity and needs. This coordination is currently being done manually at the coordination meetings, i.e. there is a lack of an IT-system, which could do the coordination work (cf. Duggal et al., 2015).

The description of the coordination activities points at the need of introducing healthcare matching as a method for coordinating patients effectively. The term coordination is frequently used in Region Skåne. In theory, the verb coordinate is used in the meaning of expressing an action followed by a thing or a person, for example to coordinate referrals or patients. In the coordination process, a one-way communication is performed. Contrary to coordinate, matching also expresses an action, between the patient and the physician, across boundaries. In that sense, matching indicates an interaction. On that specific basis, we claim that it is insufficient to use the one-way concept coordination when forming value creating processes, that optimize the accessibility.

\section{Coordinating care to the patients of Region Halland}

Drawing on Nordgren (2012, pp. 348-350, see below) the care guarantee service will be analysed based on information given by the head care coordinator in Region Halland (former named Halland County Council):

"In connection with the patient visiting local healthcare, in the form of a district medical officer, this doctor will write, as and when necessary, a referral to a specialist clinic. As there is no formal referral requirement, the patient can make his/her own request for care. The specialist clinic assesses the referral and then sends confirmation of it, containing information about the place and time of treatment, to the patient within 90 days. If this time limit cannot be guaranteed by the clinic, the patient will be able to contact the care guarantee service, by phone or email, to obtain support and service. The care guarantee service has agreements with clinics in Halland County, in the fields of orthopaedics, urology, eye care, and surgery, which can be contacted by the care guarantee service. If there are no agreements with clinics, the care guarantee service will use its networks and the website "Waiting times in healthcare" to obtain details of free capacity. It often takes a few hours to find details of free capacity.

In order to be able to develop this service to the patient further, improved production planning and coordination between clinicarerequired,according to thecoordinatorwho states that"The most important thing is that operation planning is conducted jointly by hospitals and that the appointment books, as they are known, are opened up, which will simplify planning in the longer term. Some clinics hold longer and others shorter times open for appointments."

According to the coordinator, the most important statement influencing professionals working for Halland County Council was made by the Chairman of the County Council Executive Committee, who was considered to be the most powerful politician at that county council: "It is not enough to set goals which are seen as legitimate. The most conclusive thing was when politicians stated that the patient was to be guaranteed $100 \%$ accessibility to healthcare, and that the clinic is not the owner of the patient anymore." This statement has influenced the organization of healthcare in Halland County.

The significance of this statement is that all patients, not $99 \%$ of them, should be offered care on time. As an effect of the political will manifested in certain statements (i.e. to guarantee $100 \%$ accessibility) in order to guarantee the patient time, it has been possible, according to the coordinator, for the County Council to reduce its waiting lists in a remarkable way. ${ }^{\mathrm{x}}$ According to the coordinator, the leaflet Guaranteed time....(Halland County Council 2009) has 
also had a considerable effect on waiting lists. This is confirmed by the Chief Executive of Halland Hospital who states that "the care guarantee has provided a great focus for all working in specialist care" (Provincial daily Hallandsposten, 26-07-2010). According to him, management of the care guarantee has been developed and old systems have been broken up. As a result, doctors are said to be in a position now to spend more time on patients, with capacity being controlled and matched week after week (ibid.). Thus, the impact of the care guarantee is on the hospital.

If time targets are not met by hospital(s), a consequence of this will be that the patient is assisted in obtaining care from another care-giver, either inside or outside his/her county council within the guarantee time. Another consequence will be the hospital being charged the full cost of the treatment, i.e. a form of negative stigmatizationwould then be caused to the hospital.

Halland County Council has achieved its goals concerning the limiting of waiting times, for 2009 and 2010. More than $98 \%$ of patients have been offered care on time during these years in Halland County (Swedish Association of Local Authorities and Regions Website 2010, 2011)."

\section{Analysis of the work of coordination of patients in Halland}

The text describes how the patient, the referrer, the clinic and the Care guarantee service unit co-create and manage the guarantee service process. The managing of the routines for referrals and waiting lists is of great importance (Nordgren, 2012). The operation planning has to be conducted jointly by hospitals and the appointment books should be opened up (Hall, 2011). Moreover the text points at using performatives: “....The most conclusive thing was when politicians stated that the patient was to be guaranteed $100 \%$ accessibility to healthcare.....", which influenced the employees in the way of increased service (Nord Councilgren, 2012, p. 349). Thirdly the leaflet Guaranteed time for appointments and treatment. Information about your care guarantee had a considerable effect on waiting lists.

Most important in the development of the service was the political statement that the care guarantee should be delivered by the employees, entailing that every patient is offered care on time. Moreover, the leaflet, and the process of co-creation of service to the patients had a considerable effect on waiting lists (Callon 2007).

\section{Summary of the two analyses of coordination}

In Region Skåne the increase of the coordination activities and the long waiting lists points at the need of introducing healthcare matching for coordinating patients.

In Region Halland the care guarantee service has been developed. Both the performative statements and the process of co-creation service have performed reality.

\section{Developing the preliminary healthcare matching model}

Following Nordgren $(2011)^{\mathrm{xi}}$ the conditions for developing healthcare matching is used as a base for the development of a preliminary conceptual model, done by the researchers in cooperation withstrategists and a physician in Region Skåne. It also usesthe conclusions from the analyses of the coordinationservice in theRegions. It is illustrated in figure 1. 


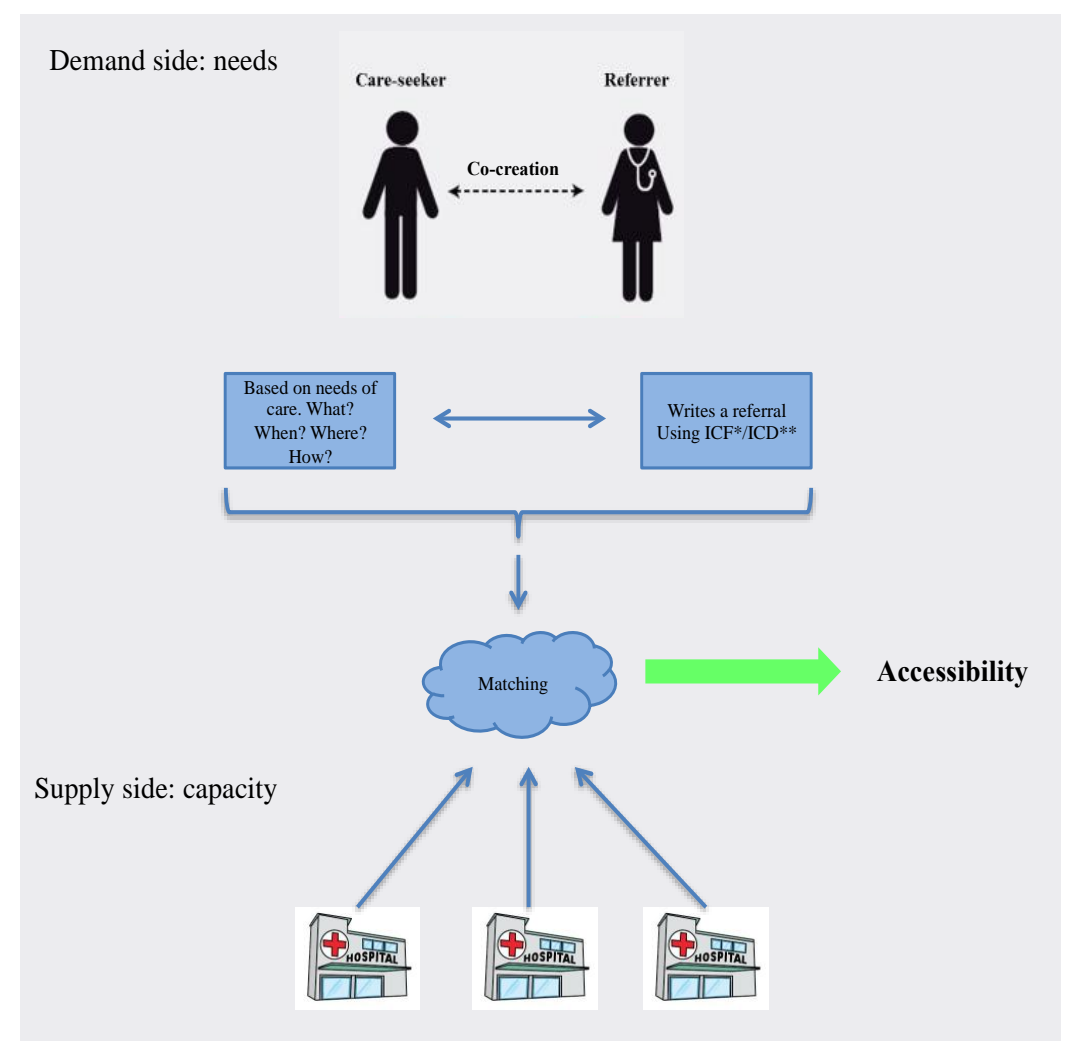

Figure 1. Preliminary healthcare matching model

* ICF - International Classification of Functioning, Disability and Health

**ICD - International Statistical Classification of Diseases and Related Health Problems

The basics of the developed healthcare matching model (figure 1) can be divided into a demand side (the care-seeker's needs) and a supply side (services provided by various healthcare units). The demand side is about the referrer in cocreation with the patient, identifying, and making a description of, this need and being able to classify which healthcare measure needs to be carried out. This is done in a care request or a referral. It is also possible for care-seekers to write referrals themselves. The need will then be assessed by the receiving clinic and who in turn can plan the necessary treatments. A standardised description of care requirements can be classified using ICF (International Classification of Functioning, Disability and Health) and/or ICD (International Statistical Classification of Diseases and Related Health Problems),e.g. impaired vision degree $\mathrm{xx}$ in left eye (ICF codable) due to cataracts (ICD). Following that, a carerequest can be made by the referrer. This, too, is standardised and is normally constituted by the referral. In the care request, attention has to be paid to potential complications and to the care-seeker's specific profile (parameters) when the care request is being produced. Once it has been implemented, each measure is given a certain value. For the referrer matching the care to the care-seeker, access to information is required concerning the range available.

The supply side (figure 1) consists of a description of the healthcare units and the services that these are able to provide. These services are defined according to a joint service catalogue. This range is classified using the National Board of Health and Welfare's codes for classifying healthcare measures, e.g. cataract operation, code zz. Exactly which services to be provided by the respective healthcare unit must be online so that there is certainty regarding which range is available. To the catalogue, it is appropriate to attach an open appointment book for doctors to enable booking suitable times.

The various actors interacting in the matching process include the care-seeker, the doctor, the different healthcare units and an independent matching unit. Consequently, the matching (see figure 1) is managed by an organisational digital matching unit on the regional or the national level, constituting an independent intermediary between the care-seeker and healthcare providers. This unit coordinates the demand and the supply sides, hence diminishing the surplus and the deficits of capacity of different healthcare units. 
The starting point is that care-seekers want to use their freedom of choice and care guarantees. The model is based on cooperation between healthcare units with available capacity within a certain area, having the ability to offer this to another unit that lacks capacity and vice versa, with the aim of creating offerings for the care-seeker (cf. Qu et al., 2007). The units are being pooled through matching. Each unit is unique regarding the range of services, technology, premises, and delivery times.

A combined overview is required, of the range of available services for the respective healthcare unit and the possibility for care-seekers and their referrers to reserve this capacity. County council boundaries or public/private must not be an obstacle to making a reservation; instead, there must be incentives for cooperation.

Several of the conditions for the development of a matching model in turn place demands on cooperation between county councils, between hospitals as well as between hospitals and district health centres (see the next section). The organizational implications of a matching model is that it can match capacity within and between units interactively with the patients and is applicable in different organizational areas (Nordgren, 2011).

\section{Barriers to healthcare matching}

Healthcare matching is based on inter-organisational cooperation, which is not unproblematic. Cooperation strategies in general entail interactions between actors with different backgrounds, goals, and knowledge coming together for joint efforts. It is a matter, for instance, of roles, responsibility, and relationships and concerns issues of affiliation and shared conceptions. Many taken-for-granted principles of organising within one organisation can result in entirely different consequences in an inter-organisational relationship. Uncertainty, unclear boundaries, diffuse expectations, conflicts of interests and values, and cultural differences are all aspects which can exist as problems when collaboration initiatives in general are put into practice (Planander, 2002, 2004; Huxham \& Vangen, 2005; Gulati, 2009).

Concerning healthcare matching it is a matter of the care-seeker being proposed alternatives, based on a context in which different actors are involved. For the care-seeker, it is important for this cooperation between the actors to work in order for him/her to be able to experience continuity during the care process. However, the driving forces behind the evolution of healthcare have not focused on facilitating the development of systems that coordinate care for the patients (Anell, 2004). Instead, it may be the case that many elements of the healthcare profession, and its practice, constitute obstacles to cooperation. The vertical division of medical work and the inadequate continuity for the patient are areas that counteract possibilities of cooperation (Vinge, 2005). Instead, the horizontal aspect of organising should become underlined (Gulati, 2007).

Concerning accessibility and healthcare matching, we could speak of barriers, which impede matching. Therefore, several conditions have to be met in order for a healthcare matching to be able to develop. It is a matter of advanced knowledge that concerns the care-seeker's needs and possibilities of interacting in the system, rules governing the freedom of choice that are made known, available information of capacity across boundaries, something also applicable to coordinated IT systems for administrative support and capacity matching. Likewise, incentives are needed for cooperation across institutionalised boundaries (ibid). It is thus a question of a complex situation containing different conditions. Several changes to established work routines and IT systems in healthcare (concerning pathways) and the development of new work routines and IT systems have to be made (Dent \& Eason, 2014).

Different cultures and cultivated routines are to be dissolved and new ones developed. As Axelsson \& Axelsson (2006) states differences in values and cultures are the most difficult barriers to integration. Adaptation and understanding of the respective party's perspective and background constitute a very important part of the collaboration process (Bihari Axelsson \& Axelsson, 2009). The fact that the development of cooperation efforts across organisational boundaries costs and takes time is important but often overlooked. The involved actors' different cultures can constitute a very conspicuous barrier (Axelsson \& Axelsson, 2006). The differing interests of separate actors can encourage direct or indirect resistance to current changes since these can entail shifts of power and encroach upon these different actors' influence or autonomy, in the case of politicians, county council managers and healthcare staff (Winblad, 2007).

The Swedish county council legislation was developed as far back as the 1860 s and is based on the distribution of the county councils' self-governance whereby these are primarily responsible for their own citizens' welfare and wellbeing (Gustafsson, 1987). These organisational and institutional prerequisites constitute strong traditions, but also contain minor incentives to cooperate across county council boundaries. This also manifests itself in the politicians' reluctance to cooperate (Winblad, 2007). One example of this kind of geographical barrier is that a patient does not receive compensation for sick leave to another hospital in another region if a specialist referral is missing. 


\section{Politically inherited and interwoven traditions.}

The distribution of Sweden's political power is rooted in the strongly developed devolution of political decisionmaking to county councils and municipalities (ibid.) This manifests itself, for example, in politicians seeing themselves as representatives of democracy on a highly superordinate level where strong traditions of public governance remain, despite notions of the individual's freedom of choice and autonomy (ibid).

We argue that these traditions of putting the home county council's citizens at the forefront are in partial conflict with the notion of the care guarantee, which concerns the need to see to patients across county council boundaries. Similarly, it is in conflict with the cooperation across these institutional boundaries.

\section{Professional identity and interests.}

One prominent group in healthcare is the physicians who represent a profession where specialisation, norms, and independence are especially characteristic (Berlin \& Kastberg, 2011). It is not uncommon for these professions to have a strong desire to safeguard their own specialist area. The actors are strongly incentivised to develop their own knowledge, to practice (Persson \& Westrup, 2009). In this area, a tradition has also developed of seeing queues as something positive. To get to grips with the problems, the government has invested major economic resources in compensating county councils that have shortened queues (Nordgren, 2012).

The administrative systems (as budget systems) constitute an extensive and important part of organising healthcare (Berlin \& Kastberg, 2011). These systems often differ between county councils, thus counteracting the coordination and matching notions.

Moreover there are different tendencies within medico-technological developments and the organisational design, where specialisation, bureaucratisation, and economies of scale are powerful driving forces (from healthcare's point of view) that may be pulling in different directions bringing consequences which are partially in conflict with the intentions that exist around the care guarantee, freedom of choice and accessibility (from the customer's perspective). The discussion concerning accessibility to care can sometimes be perceived more as a rhetorical element than as a real policy (Nordgren, 2010).

What we are able to find as a common denominator in several of the different barriers discussed is the issue of understanding the whole and the element of incentive. In general, the creation of shared conceptions and the management of unclear boundaries and diffuse expectations are recurring themes when cooperation across organisational boundaries is discussed, regardless of whether it concerns the private or the public sector (Planander, 2002; Huxham \& Vangen, 2005; Hibbert et al., 2008).

Finally, we argue that it is not least a matter of making visible the cooperation incentives for the actors involved, i.e. creating a win-win situation whereby the different actors involved feel that they themselves can "earn" from a changed attitude. The existing incentives, that are present in the political and organisational areas, can in the worst case, be seen as conflicting with a cooperation solution. At the same time, it may be the case that the multiple organisational changes that have taken place over the years have caused certain "tiredness" in the actors involved (especially healthcare staff), which can be an obstacle to further change. The notion of healthcare matching can then be a shared but independent organisational function that matches supply and demand, and which constitutes an intermediary between patients and healthcare providers.

\section{Conclusion}

Healthcare matching is discussed as a concept, and is developed as an approach to improve accessibility to care based on experiences from two regions in Sweden. Matchingenablesto avoidad hoc resource decisions in order to reducequeues. In contrast to coordination of healthcare, which is about one-way action in giving care, matching accentuates the interaction, i.e. co-creation, between patients, referrers and providers. Account is taken to both specific patient-related needs and capacity of different kinds.

The first conclusion is that there is a need for healthcare matching being useful at the different levels of integration of healthcare services. Thereby is indicated that matching could be included in a continuum where pooling of resources implies an advanced matching in order to balance capacity to the needs of the patients. Matching accentuates the twoway interaction, i.e. the co-production, between patients and providers.

The second conclusion is that healthcare providers could benefit from using matching through a healthcare matching model. The matching may take place online via an independent matching unit offered to the care-seeker and the referrers. Fundamental is the situation whereby the care units cooperate and co-create value together. 
In order to achieve this matching, several barriers must be paid attention to. One of the barrier elements concerns the legislation that includes minor incentives to cooperate across county council boundaries. The underlying tendencies concerning medico-technological developments and the organisational specialisation of healthcare, economies of scale and bureaucracy, are partially conflicting notions about freedom of choice and accessibility seen from the patient's perspective. Other barriers include the traditions of strongly devolved political decision-making and the associated boundaries between county councils. The strong professional identity, whereby the safeguarding of your own profession's special field dominates, also constitutes obstacles concerning matching.

The findings in this article is in line with Epstein et al (2010) and Duggai et al. (2015). The difference is that this article develops an overall model of healthcare matching, while the research made by Epstein et al (2010) and Duggai et al. (2015) indicates important aspects of matching as specialization of physicians and matching of patient records.

The implication of this article is that in order to create good accessibility to healthcare, it is of value to match patients and referrals to the applicable skilled physicians and to treatment in time. Furthermore, it is necessary to cooperate between different organizational units and across barriers.

\section{Limitations}

The result from this study comes from research within two regional settings. The result might still be applicable in other regions since the organization of the Swedish healthcare does not differ between regions in a way that will impede a matching model to operate.

\section{References}

Ahgren, B. (2014), "The path to integrated healthcare: Various Scandinavian strategies", International Journal of Care Coordination, Vol. 17 No. 1-2, pp. 52-58.

Ahgren, B. \& Axelsson, R. (2005), "Evaluating Integrated Health Care: a Model for Measurement", International Journal of Integrated Care, Vol. 5 No. 3.

Anell, A. (2004), Strukturer Resurser Drivkrafter, Studentlitteratur, Lund.

Batalden M, Batalden P, Margolis P, et al (2016), Coproduction of healthcare serviceBMJ Qual Saf 2016;25:509-517.

Berlin, J. \& Kastberg, G. (2011), Styrning av hälso- och sjukvård, Liber, Malmö.

Berry, L.L., \& Bendapudi, N. (2007), "Health care: a fertile field for service research", Journal of Service Research, Vol. 10 No. 2, pp. 111-122.

Bihari Axelsson, S. \& Axelsson, R. (2009), "From territoriality to altruism in interprofessional collaboration and leadership", Journal of Interprofessional Care, Vol. 23 No. 4, pp. 320-330.

Axelsson, R. \& Bihari Axelsson, S. (2006), "Integration and collaboration in public health-a conceptual framework", International Journal of Health Planning and Management, Vol. 21.pp. 75-78.

Callon M. (2007) "What does it mean to say that economics is performative?", in Do Economists Make Markets?, eds D. MacKenzie, F. Muniesa and L. Siu, Princeton University Press,Princeton, NJ, pp. 311-357.

Cederqvist, J. (Ed.). (2008), Recept för vården. Om effektivitet i sjukvården och äldreomsorgen, (Prescriptions for Healthcare, on efficiency in health care and elderly care), SNS 2008, Stockholm.

Czarniawska, B. (2007), Shadowing and Other Techniques for Doing Fieldwork in Modern Societies, Liber AB, Copenhagen Business School Press, Universitetsforlaget, Malmö.

Dent, M. \& Eason, K.D. (2014), "Electronic information in health and social care - promises and pitfalls", Health Informatics Journal, Vol. 20 No. 3, pp. 165-167.

Diamond, P.A. (1982), "Aggregate Demand Management in Search Equilibrium”, The Journal of Political Economy, Vol. 90 No. 5, pp. 881-894.

Duggal, R., Kumar Khatri, S. \& Shukla, B. (2015), "Improving Patient Matching: Single Patient view for Clinical Decision Support using Big Data Analytics", in Reliability, Infocom Technologies and Optimization, proceedings of the $4^{\text {th }}$ International Conference, pp. 1-6.

Epstein, A.J., Ketcham, J.D. \& Nicholson, S. (2010), "Specialization and matching in professional services firms", RAND Journal of Economics, Vol. 4 No. 4, pp. 811-834.

Eriksson, E., Nordgren, L. (2018). "From one-sized to over - individualized? Service logic's value creation." Journal of Health Organization and Management. Vol. 32 Issue: 4, pp.572-586.

Fieldston, E., Zaoutis, L., Hicks, P., Kolb, S., Sladek, E., Geiger, D., Agosto, P., Boswinkel, J. \& Bell, L. (2014), "Front-Line Ordering Clinicians: Matching Workforce to Workload". Journal of Hospital Medicine, Vol. 9 No. 7, pp. 457-462.

Gulati, R. (2007), "Silo busting: How to Execute on the Promise of Customer Focus", Harvard Business Review, Vol. 85 No. 5 , pp. $98-108$. 
Gulati, R. (2009), Reorganize for Resilience, Harvard Business Press, Boston.

Gulati, R., Wohlgezoogen, F., \& Zhelyazkov, P. (2012). "The Two Facets of Collaboration: Cooperation and Coordination in Strategic Alliances". The Academy of Management Annals, 6(1), 531-583.

Gustafsson, R.Å. (1987), Traditionernas ok. Den svenska hälso- och sjukvårdens organisering i historie-sociologiskt perspektiv, Esselte Studium AB, Falköping.

Hall, R. (2011), Handbook of Healthcare System Scheduling, Springer, New York.

Halland County Council (2009) Guaranteed time for appointments and treatment. Information about your care guarantee, Leaflet, Halmstad.

Socialstyrelsen, (2018), Tillgänglighet i hälso- och sjukvården, Februari 2018. (National Board of Health, (2018), Accessibility in Health Care, February 2018)

SWEDEN. SE, HEALTH CARE IN SWEDEN, 2018-04-05.

Hibbert, P., Huxham, C. \& Ring, P. S. (2008), "Managing Collaborative Inter-Organizational Relations", in S. Cropper, M. Ebers, C. Huxham \& P.S. Ring (Ed.), The Oxford Handbook of Inter-Organizational Relations, Oxford University Press, Oxford, pp. 390-416.

Huxham, C. \& Vangen, S. (2005), Managing to Collaborate - The Theory and Practice of Collaborative Advantage, Routledge, Abingdon.

Iversen, T. (2014), Aktuelle utfordringer i helsesektorene i Norden. Speech, KEFU, Lund.

Landstingsrevisionen. (2013), Granskning av landstingets system för dimensionering och matchning av vårdplatser, Report No. 06/2013.

Lovelock, C. \& Wirtz, J. (2007), Services Marketing People, Technology, Strategy, Prentice Hall, Person.

Myndigheten för vård- och omsorgsanalys. (2016), Hinder och möjligheter för att öka patientlagens genomslag, Report 2016:1. Stockholm.

Nilsson, M. (2016), Samordning av patienter i Region Skåne, Yearly report.

Nilsson, M. (2017), Samordning av patienter i Region Skåne, Yearly report.

Nilsson, M. (2019), Statement 2018-12-16.

Nordgren, L. (2003), Från patient till kund. Intåget av marknadstänkande i sjukvården och förskjutningen av patientens position. Phd dissertation, Lund: Lund Business Press.

Nordgren, L. (2009), "Value Creation in Health Care Services - Developing Service Productivity - Experiences from Sweden", International Journal for Public Sector Management, Vol. 22 No. 2, pp. 114-127.

Nordgren, L. (2010), "Mostly empty words - What the discourse of 'choice' in health care does", Journal of Health Organization and Management, Vol. 24 No. 2, pp. 109-126.

Nordgren, L. \& Ahgren, B. (2010), "Val av primärvård: resultat från en brukarundersökning baserad på invånarepaneler. Commissioned research report" 2010:3, Swedish Competition Authority, Stockholm.

Nordgren, L. (2011), "Healthcare matching - Conditions for developing a New Service System in Healthcare", International Journal of Quality and Service Sciences, Vol. 3 No. 3, pp. 304-318.

Nordgren, L. (2012), "Guaranteeing healthcare - what does the healthcare guarantee discourse do?", Financial Accountability \& Management, Vol. 28 No. 3, pp. 335-354.

Normann, R. \& Ramiréz. R. (1994), 'From Value Chain to Value Constellation: Designing Interactive Strategy', Chichester: Wiley,

Normann, R. (2001), Reframing business; when the map changes the landscape affärslandskapet, Chichester: Wiley.

Osborne, S.P. (2018), From public service-dominant logic to public service logic: are public service organizations capable of co-production and value co-creation? Public Management Review, Vol. 20 No. 2, pp. 225-231.

Persson, J.E. \& Westrup. U. (2009), "Fragmented structure and vertical control systems: The Swedish experience of resource utilization in human services", International Journal of public Sector Management, Vol. 22 No. 15, pp. 400-409.

Planander, A. (2002), "Strategiska allianser och förtroendeprocesser - en studie av strategiska samarbeten mellan högteknologiska företag", Dissertation, Lund University, Lund Business Press, Lund.

Planander, A. (2004), "Identity and Identification in a Context of Competition", Conference paper presented at EIASM workshop on coopetition strategy: Towards a new kind of dynamics?, Catania, Italy, September 16-17.

Qu, X., Rardin, R., Williams, J. \& Willis, D. (2007),"Matching Daily Healthcare Provider Capacity to Demand in Advanced Access Scheduling Systems", European Journal of Operational Research, Vol. 183 No. 2, pp. 812826.

Region Skåne (2013). "Praxis ofcoordinationof patients inthe Region of Skåne".

Region Skåne (2015). Seven meetings with the care coordinators 2013-- 2015.

Region Skåne's auditors (2013). "Report no. 1 Review of accessibility coordination".

Roth, A.E. (2015), Who Gets What - and Why, Houghton Mifflin Harcourt, New York. 
SOU (2016:2), "Effektiv vård. Slutbetänkande av en nationell samordnare för effektivare resursutnyttjande inom hälsooch sjukvården", Elanders Sverige $\mathrm{AB}$, Stockholm.

Steiner, P. (2010), "Gift-giving or market? Economists and the performation of organ commerce", Journal of Cultural Economy, Vol. 3 No. 2, pp. 243-259.

Van de Ven, A., H. (2007), Engaged Scholarship - a Guide for Organizational and Social Research, Oxford University Press, Oxford.

Vargo, S. L. \& Lusch, R. F. (2004), "Evolving to a New Dominant Logic for Marketing”, Journal of Marketing. Vol. 68, pp. 1-17.

Vinge, S. (2005), "Arbejdsorganisering og organisationsförståelse i sygehussektorn”, Nordiske OrganisasjonsStudier 2005, Vol. 2, pp. 99- 113.

Wingner Leifland, C. \& Nordgren, L. (2017). Koordinering och matchning inom hälso- och sjukvård - utveckling av en värdeskapande tjänst för vården. Kefu Skriftserie, 2017:1. Lunds Universitet.

Winblad, U. (2007), "Valfriheten: en misslyckad sjukvårdsreform?", in Blomqvist, P. (Ed.). Vem styr vården? Organisation och politisk styrning inom svensk sjukvård, SNS Förlag, Stockholm, pp. 132-156.

Winblad, U. \& Hanning, M. (2013), "Sweden”, in Siciliani, V. Borowitz, M. and Moran, V. (Ed.), Waiting Time Policies in the Health Sector: What Works?, pp. 275-292, OEC

Notes

${ }^{\mathrm{i}}$ In Cederqvist (2008) several patients describe how they have had to wait, have met the "wrong" physician and been misunderstood (Nordgren, 2009). Examples of coordination in practice are theCare Guide andtheprivate health insurance (Nordgren, 2011).

ii The coordination of waiting patients in specialist care in the Skane region has increased. In 2016, 22079 patients were coordinated compared with 1869 in 2006 (Nilsson, 2016).

iii The Health and Medical Service Act regulates the responsibilities of county councils and municipalities, and gives local governments more freedom in this area. The role of the central government is to establish principles and guidelines, and to set the political agenda for health and medical care. It does this through laws and ordinances or by reaching agreements with the Swedish Association of Local Authorities and Regions, which represents the county councils and municipalities.... Responsibility for providing health care is devolved to the county councils and, in some cases, municipal governments. Swedish policy states that every county council must provide residents with goodquality health and medical care, and work to promote good health for the entire population (HEALTH CARE IN SWEDEN. SE, 2018-04-05).

${ }^{\text {iv }}$ Waiting times for pre-planned care, such as cataract surgery, have long been a cause of dissatisfaction. As a result, Sweden introduced a care guarantee in 2005. This means that all patients should be in contact with a community health care center the same day they seek help and have a doctor's appointment within seven days. After an initial examination, no patient should have to wait more than 90 days to see a specialist, and no more than 90 days for an operation or treatment, once it has been determined what care is needed. If the waiting time is exceeded, patients are offered care elsewhere.

${ }^{v}$ According to the Royal Swedish Academy of Sciences, which selected the winners of The Swedish National Bank Prize in Economic Sciences in Memory of Alfred Nobel 2012 “The combination of Shapley's basic theory and Roth's empirical investigations, experiments and practical design has generated a flourishing field of research and improved the performance of many markets." Their research focuses on markets, which do not use prices to match supply and demand.

${ }^{\text {vi }}$ Matching is often used in conjunction with the labour market (Diamond, 1982).

viii Based on Roth's research, Steiner (2010) discusses matching of donors to recipients. He (p. 254) claims that: "Markets match supply and demand not simply by the price mechanism alone, but thanks to other forms of commerce, such as personal relationship and a wide variety of market devices."

${ }^{\text {viii }}$ To coordinate entails the coordination of various operations and activities between units in the benefit of patients (Gulati, 2007). The term cooperation encompasses the more general aspects of "working together" (Gulati et al., 2012).

ix "the application of specialised competencies (knowledge and skills) through deeds, processes, and performances for the benefit of another entity or the entity itself"' (Vargo and Lusch 2004, p. 2).

${ }^{\mathrm{x}}$ Waiting lists were reduced in several county councils (Winblad, 2010).

${ }^{x i}$ Healthcare lacks incentives and structures of matching capacity between various care providers and for coordinating episodes of care for patients (Nordgren, 2011, p. 304). 